\title{
State-of-the-art for CAR T-cell therapy for chronic lymphocytic leukemia in 2019
}

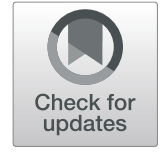

Richard Lemal ${ }^{1,2^{*}}$ (iD and Olivier Tournilhac ${ }^{2}$

\begin{abstract}
Experience in the use of CAR T cells to treat CLL is limited, but safety and efficacy data are encouraging, suggesting that it may be possible to use CAR T cells in populations of CLL patients with particularly unfavorable prognoses. Mechanisms intrinsic to the pathophysiology of CLL undoubtedly explain the efficacy reported based on limited data for the first few series, and underlie the rationale of successive modulations in lymphodepletion schemes, transgene constructs, and, finally, the therapeutic association of CAR T cells with ibrutinib, which appears to be particularly promising. This review describes the published results and expected developments.
\end{abstract}

Keywords: CLL, CAR T cells, Ibrutinib

\section{Introduction}

Chronic lymphocytic leukemia (CLL) is the most common lymphoid hemopathy (estimated incidence of 2 to 4 cases per 100,000 inhabitants/year). It is diagnosed at a median age of 72 years, and therefore mostly in patients with comorbid conditions [1]. It is a B lymphoid hemopathy characterized by invasion of the bone marrow, blood, and secondary lymphoid organs (spleen and/or lymph nodes). Prognosis is evaluated essentially on the basis of cytogenetic and molecular biology analyses. The two most unfavorable elements associated with a poor prognosis are: 1) p53 alterations (17p deletion and/or TP53 gene mutation), which weaken the response to cytotoxic agents, and 2) a complex karyotype (with more than three abnormalities) [1]. Treatment indications are based on the progressivity criteria of the International Workshop on CLL (IWCLL) [2]. The recent development of BCR pathway inhibitors (BCRi; Bruton Tyrosine Kinase (BTK) and PI3K $\delta$ inhibitors) and BCL2 inhibitors (BCL2i) has completely modified the therapeutic landscape of CLL [3], but the extent of these changes remains unclear [4]. However, patients with relapses or with tumors refractory to such treatments still have an unfavorable

\footnotetext{
* Correspondence: rlemal@chu-clermontferrand.fr

${ }^{1}$ Histocompatibility laboratory, CHU Clermont-Ferrand, INSERM CIC501, EA 7453 -Université Clermont Auvergne, Clermont-Ferrand, France

${ }^{2}$ Adult Clinical Hematology, CHU Clermont-Ferrand, INSERM CIC501, EA 7453

-Université Clermont Auvergne, Clermont-Ferrand, France
}

prognosis. Hematopoietic stem cell allografts (generally followed by monitoring and preemptive treatment of residual disease [5]) remain a possible treatment, but its use is clearly declining [6] and is generally reserved for rare eligible CLL patients with a very poor prognosis.

$\mathrm{T}$ cells bearing a chimeric antigen receptor (CAR $\mathrm{T}$ cells) are generated by genetic engineering, and are designed to arm the immunocompetent $\mathrm{T}$ cells of the patient with an activating receptor consisting of 1) an extracytoplasmic variable fragment of an immunoglobulin (scFv) directed against a tumor target, 2) an intracellular T-cell receptor activation molecule $(\mathrm{CD} 3 \zeta)$ and 3) positive costimulation molecules (generally CD28 and/or 4-1BB) [7]. The result is a population of immune cells, mostly $\mathrm{T}$ lymphocytes, capable of recognizing a tumor target without Major Histocompatibility Complex (MHC) restriction, and destroying that target through cytotoxic effector mechanisms. The most advanced CAR T cells developed to date are directed against CD19: tisagenlecleucel and axicabtagene ciloleucel, both released onto the market in the United States and Europe in 2017/ 2018, tisagenlecleucel for use against pediatric B acute lymphoblastic leukemia (B-ALL) and diffuse large Bcell lymphoma (DLBCL) in relapse or refractory to standard immunochemotherapy treatment and axicabtagene ciloleucel for DLBCL only [7]. 
CLL was one of the first diseases in which CAR T cells were used [8], but experience with the use of this treatment is currently less extensive for this disease than for B-ALL or DLBCL. The objective of this review is to discuss the main results obtained with CAR T cells in CLL and to consider likely developments.

\section{Efficacy data}

Since the first report of the efficacy of second-generation CAR T cells against CLL in 2011 [8], results have been published or reported for the injection of CAR T cells into 134 CLL patients [8-22]. The clinical status of these patients is reported in Table 1, together with the CAR $\mathrm{T}$ constructs and lymphodepletion schemes used.

The first observation to emerge from these results is that the population of treated patients had a particularly poor prognosis. The median age of the patients treated was 61 years (range: 40 to 77 years), and most were in relapse after a large number of lines of treatment. Overall, 68 patients had already received ibrutinib [14, 15, 18, 20-22], 25 had already received venetoclax $[18,20,22]$, nine were in postallograft relapse $[12,16]$, and 12 were treated in the context of transformation into refractory high-grade lymphoma (Richter's syndrome) $[12,13,18,20]$. In addition, 74 of the 108 patients evaluated (68.5\%) had p53 alterations, and 41 of the 70 patients evaluated (58.6\%) had a complex karyotype (see Table 1).

It is not straightforward to integrate these data, but a second observation that emerges is that efficacy is lower for CLL than for B-ALL and DLBCL: a complete response (CR), according to the IWCLL criteria, was obtained in only a minority $(20-30 \%)$ of patients [14, 18], and progression-free survival (PFS) estimated at $25 \%$ at 18 months [14, 23]. Responses appear to be weaker in the lymph nodes than in the bone marrow and blood. Furthermore, these results should be considered in light of the frequency of complete bone marrow responses with undetectable minimal residual disease (MRD) reported in some series [18, 20-22], which has been correlated with PFS and OS close to $100 \%$, with a median follow-up of 6.6 months [18]. It is difficult to determine the precise response to CAR $\mathrm{T}$ cells specifically in patients with Richter's syndrome from published data, but this response is objective, with a possible decrease in lymph-node tumor syndrome. However, it appears to be partial and transient, and insufficient for the moment to improve the very poor prognosis of these patients $[12,13,18,20]$.

Promising data have also been obtained for the use of allogeneic CAR $\mathrm{T}$ cells derived from lymphocytes from hematopoietic stem cell donors in the context of postallograft relapse $[12,16]$. Response rates remain low in these patients with a poor prognosis, but there are signs of efficacy, and the absence of graft-versus-host disease (GVHd) is highly reassuring.

\section{Past and future improvements}

As for other CAR $\mathrm{T}$ cell indications, there have been many improvements in lymphodepletion schemes and the construction of chimeric receptors.

Lymphodepletion was initially achieved with cyclophosphamide treatment alone, but today, it is almost always achieved with a combination of cyclophosphamide and fludarabine (see Table 1). This lymphodepletion procedure makes it possible, in particular, to improve the expansion and persistence of CAR T cells via hypothetical mechanisms such as the decrease in residual tumor mass, the induction of inflammation, the release of tumor antigens, and the decrease in the number of regulatory cells. The immunodepression induced by such lymphodepletion may also decrease the risk of immunization against the extracytoplasmic immunoglobulin variable fragment of CAR $\mathrm{T}$ cells, which is mostly of murine origin.

Alternatives to the currently preferred antigenic target in B lymphoid hemopathies, CD19, exist and may prove to be more effective or safe. For example, the use of clonal anti-light chain (kappa or lambda) CAR T cells would, theoretically, spare half the B-cell compartment and limit agammaglobulinemia [17]. CD23, the receptor of the invariant fragment of IgM ( $\mathrm{Fc} \gamma \mathrm{R})$, or ROR1 (tyrosine kinase-like orphan receptor 1 ) are also potentially interesting targets, as they are relatively specific to the B-cell tumoral compartment of CLL [24-26].

The use of CAR $\mathrm{T}$ cells combining the variable fragment and the $\mathrm{CD} 3 \zeta$ chain with a co-stimulatory molecule of CD137 (or 4-1BB), rather than CD28, which was used in the first trials $[8,10,14,21]$, or in association with $\mathrm{CD} 28[18,20,22]$ made it possible to optimize the anti-leukemic effect of CAR T cells and to improve their long-term expansion and persistence via mechanisms that are still only partially understood [27].

The use of a variable fragment of humanized immunoglobulin in the construction of CAR T cells [21] should make it possible to limit the risk of immunization against the variable fragment, as most of the fragments used originate from mice, thereby improving the longterm maintenance of the CAR $\mathrm{T}$ population. Control over the CD4/CD8 ratio of the injected CAR T cells [22] could also improve the management of the CAR T cell expansion and long-term maintenance phases.

Finally, it is clear that disease persistence at time on injection has an impact on the expansion and maintenance of CAR T cells, and the composition of the expanding population: indeed, the CAR T cells of CLL patients displaying a $\mathrm{CR}$ at the time of injection expand more 


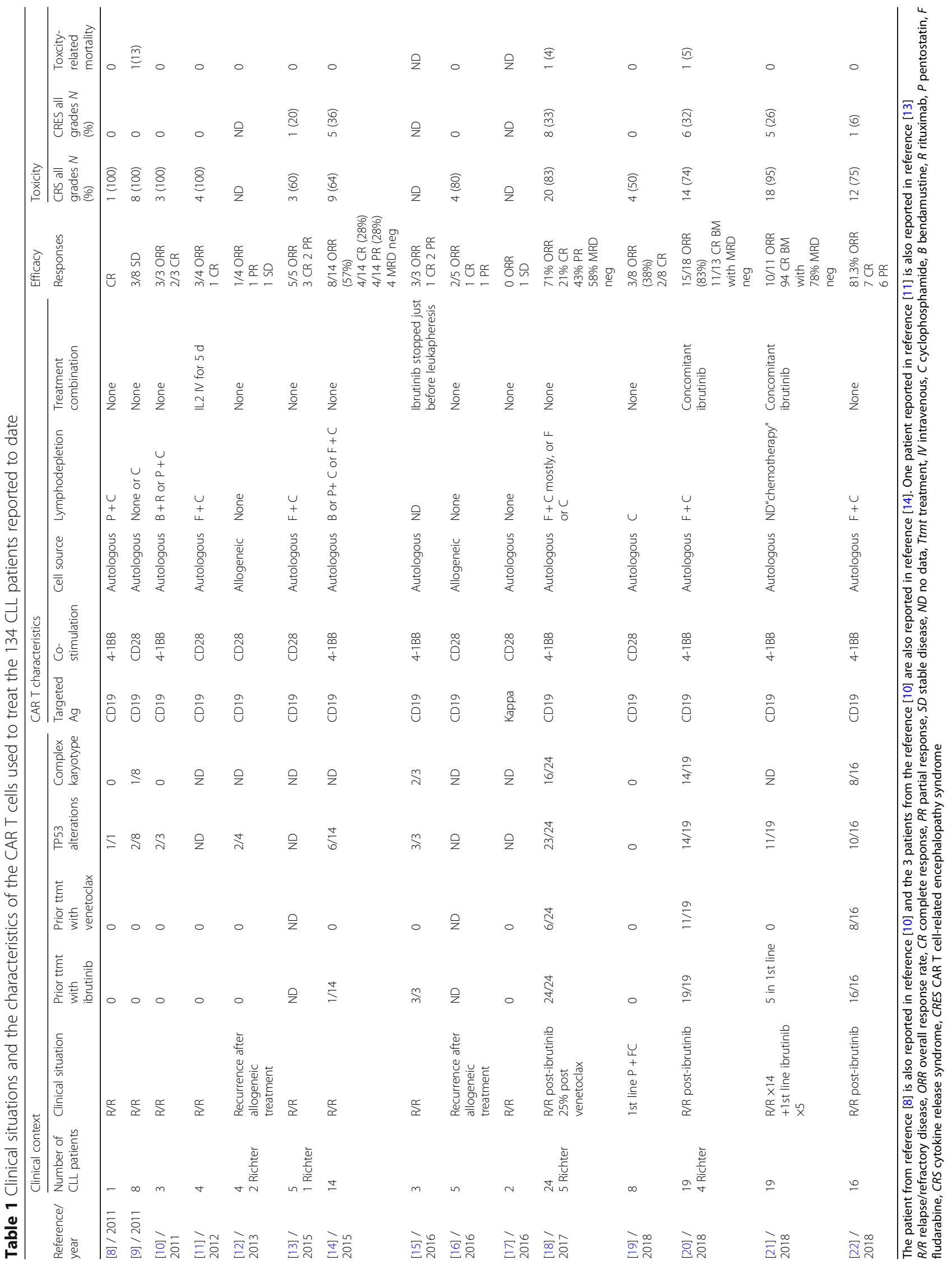

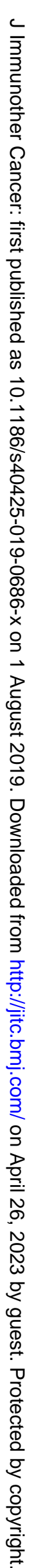


effectively and have a cytokine profile favoring their cytotoxic function and better long-term maintenance $[23,28,29]$. In addition, toxicity is lower when the residual tumor mass is limited at the time of CAR T-cell injection. These findings argue for administration earlier in the course of the disease, to ensure that the best possible response is obtained.

\section{Immunosubversion in CLL: an obstacle for CAR T cells}

The lower efficacy of CAR T cells in CLL may be partly due to the intrinsic characteristics of the immune system in CLL, which is exhausted by diverse immunosubversion mechanisms, decreasing CAR T-cell activation after transduction.

Indeed, the CD4+ $\mathrm{T}$ cells of CLL patients have an exhausted phenotype (strong expression of PD-1, CD160, and CD244) and their CD8+ T cells have low proliferative and cytotoxic capacities [30]. These intrinsic characteristics of CLL immune cells are present at the time of diagnosis, but are also favored by previous lines of treatment (with fludarabine, in particular).

The ex vivo expansion and transduction capacities of $\mathrm{T}$ cells from CLL patients are clearly different from those of $\mathrm{T}$ cells from healthy subjects. In particular, $\mathrm{T}$ cells from CLL patients display less expansion of so-called "naïve" $\mathrm{CD} 4+\mathrm{T}$ cells, an essential criterion for the long-term activity of CAR T cells. Moreover, the naïve CD4+ T cells that manage to expand from the autologous samples of CLL patients express more exhaustion markers [28].

These data support a rationale of developing allogeneic CAR T cells from a healthy donor, in whom the capacity of $\mathrm{T}$ cells to expand and their cytotoxicity are not modified by the tumor clone.

\section{Ibrutinib for CAR T cell optimization?}

Ibrutinib has already revolutionized the routine management of CLL, but it may also improve outcomes in CLL patients receiving CAR T cells.

Indeed, particularly promising rates of response to CAR $\mathrm{T}$ therapy were reported in three studies. In 2016, Fraietta et al. reported their experience with this treatment, which was limited to three patients who stopped taking ibrutinib just before the leukapheresis preceding CAR T therapy. A response was observed in all three patients, including complete remission in one case, despite the absence of lymphodepletion [15]. At the last American Society of Hematology conference, two groups reported results for two series of 19 patients receiving injections of structurally different CAR T cells, in combination with ibrutinib. The overall response rate was above $80 \%$ and the frequency of complete bone-marrow response with undetectable MRD exceeded 90\% [20, 21].

Many hypotheses have been put forward to explain this effect of ibrutinib, mostly based on our knowledge of the impact of ibrutinib on the immune system in CLL, which is probably still very patchy. In addition to Bruton's tyrosine kinase, ibrutinib is known to target the IL2-inducible T-cell kinase (ITK), which orients $\mathrm{T}$ cells towards a Th1 cytokine secretion profile [31]. Ibrutinib may therefore be involved in redirecting the immune response of autologous $\mathrm{T}$ cells (before and after transduction) from a Th2 profile to a Th1 profile, more favorable for the longterm expansion and maintenance of chimeric receptor-expressing T-cell populations. Indeed, the ability of ibrutinib to promote the expansion, maintenance, and cytotoxicity of CAR T cells and to promote cellular immune responses (with, in particular, a decrease in exhaustion markers, the modification of cytokine secretion profiles, and an increase in the diversity of the $\mathrm{T}$ repertoire, etc.) has been demonstrated in vitro $[15,32,33]$.

\section{Safety data}

Cytokine release syndrome (CRS) and neurological toxicity (CRES, for CAR T cell-related encephalopathy syndrome) are, as in other indications for CAR T therapy, the most frequent complications in CLL, and their management is not different in this context [7, 34]. The incidence of these complications is variable in the small series available and it is probably still difficult to compare them: CRS occurs in 50 to $100 \%$ of patients (Grade $\geq 3$ in 25 to $60 \%$ of cases), whereas neurological toxicity is less common (0 to $35 \%$ of cases) and mostly of moderate intensity. Death attributable to the CAR T cell procedure was reported for three of the 129 patients for whom clinical outcome data are available (2.3\%).

CAR $\mathrm{T}$ cells do not appear to behave differently in CLL and in other hematological diseases in terms of the time lag to the onset of complications or the response to tocilizumab or corticosteroids, and there are, therefore, currently no specific instructions for CLL.

The use of ibrutinib before leukapheresis has been linked to a higher incidence and greater severity of CRS in first series [18], but the concomitant administration of ibrutinib and CAR $\mathrm{T}$ cells appears to be associated with a lower incidence of $\geq$ grade 3 CRS $[20,21]$ and lower levels of pro-inflammatory cytokines (including IL-6, IL2R $\alpha$, and MCP-1, in particular) [20].

Finally, in one case, a patient with CLL treated with CAR T cells was reported to display the proliferation of an identified population of clonal CD8+ CAR T cells carrying 1) a TET2 gene interrupted by the chimeric antigen receptor transgene and 2) a preexisting TET2 mutation in the second allele [35]. This resulted, in this particular case, in the persistence of the mutated TET2 CD8+ CAR T-cell population and complete remission of CLL more than five years after injection. This example, presented as an opportunity by the authors, should make us think carefully about the relatively moderate control 
we have over such genetic manipulations, particularly in elderly patients who have received a number of different treatments, in whom residual hematopoiesis is fragile and oligoclonal, and about the need to follow these patients closely in the long term.

\section{Future changes in indications}

Therapeutic strategies for CLL will be dominated, in the near future, by the use of BCRi, which will be the firstline treatment in most patients, relegating immunochemotherapy to an uncertain secondary role. BCL2i is currently indicated for patients with relapses and patients intolerant to BCRi. This new strategy certainly has major advantages in terms of response and survival, but several obstacles to its use have emerged: 1 ) the use of these new drugs, often continuously until relapse is associated with adverse effects, including cardiovascular effects (for BCRi) and with very high direct costs. CAR T cells could be used early in the treatment of CLL, as an alternative. 2) The treatment of patients with relapses or refractory disease after treatment with BCRi and BCL2i and the treatment of patients with Richter's syndrome remain challenging. In these high-risk patients, CAR T cells are currently used 1) in place of HSC allografts for patients ineligible for HSC transplantation and 2) instead of HSC allografts for some patients eligible for transplantation. However, CAR T cells could ultimately be used as a complementary treatment, in addition to HSC allografts.

\section{Conclusion}

The CLL treatment paradigm has been deeply modified by the availability of new treatments including BCRi and BCL2i, allowing patients with relapsed CLL at high risk to benefit from prolonged remission periods. However, relapses remain the rule, especially in patients with adverse biological criteria such as p53 alteration, and complex karyotypes. In patients failing BCRi or BCL2i, CAR $T$ therapy offers a new opportunity that could not only replace allogeneic HCT in patients who would have been eligible, but could also be extended to older patients with a reasonable level of co-morbidity. CAR T therapy could also directly compete with targeted therapies, which because of their mechanism of action, must be administered over the long term, leading to problems of toxicity, compliance and ultimately cost.

CAR $\mathrm{T}$ therapy does not solve all the therapeutic challenge in CLL and comes with limiting toxicity in a population whose median age exceeds 70 years and which may have acquired hematopoietic alterations, whose the frequency increases with age.

The optimization of CAR T constructions is a way of improvement. But from now on, the question arises of improving the results based on the CAR-T available in practice and in particular their combination with other CLL therapies. Ibrutinib in this context has been evaluated and its maintenance at the time of injection of CARis a promising option that will be evaluated prospectively (NCT03331198). Beyond BCRi, the place of venetoclax also remains to be defined in this specific context.

\section{Abbreviations \\ B-ALL: B-cell acute lymphoblastic leukemia; BCL2: B-cell lymphoma 2; BCR: B- cell receptor; BTK: Bruton Tyrosine Kinase; CAR T cells: T-cell with chimeric antigen receptor; CLL: Chronic lymphocytic leukemia; CRES : CAR T cells related encephalopathy syndrome; CRS: Cytokine release syndrome; DLBCL: Diffuse large B-cell lymphoma; GVHd: Graft versus host disease; HSC: Hematopoietic stem cell; ITK: IL2-inductible tyrosine kinase; IWCLL: International workshop on CLL; MRD: Minimal residual disease; OS: Overall survival; PFS: Progression-free survival; PI3K $\delta$ : Phospho-inositol 3 kinase delta}

\section{Acknowledgements}

Not applicable.

\section{Authors' contributions}

Conception: RL, OT. Collection and assembly of data: RL, OT. Data analysis and interpretation: RL, OT. Manuscript writing: RL, OT. All authors read and approved the final manuscript.

\section{Funding}

Not applicable

Availability of data and materials

Not applicable

Ethics approval and consent to participate Not applicable

\section{Consent for publication}

Not applicable

\section{Competing interests}

The authors declare that they have no competing interests.

Received: 15 January 2019 Accepted: 21 July 2019

Published online: 01 August 2019

\section{References}

1. Hallek M. Chronic lymphocytic leukemia: 2017 update on diagnosis, risk stratification, and treatment. Am J Hematol. 2017;92(9):946-65.

2. Hallek M, Cheson BD, Catovsky D, Caligaris-Cappio F, Dighiero G, Döhner H, et al. iwCLL guidelines for diagnosis, indications for treatment, response assessment, and supportive management of CLL. Blood. 2018;131(25):2745-60.

3. Buske $C$, Hutchings $M$, Ladetto $M$, Goede $V$, Mey $U$, Soubeyran $P$, et al. ESMO consensus conference on malignant lymphoma: general perspectives and recommendations for the clinical management of the elderly patient with malignant lymphoma. Ann Oncol Off J Eur Soc Med Oncol. 2018:29(3):544-62.

4. Fischer K, Hallek M. Optimizing frontline therapy of CLL based on clinical and biological factors. Hematol Am Soc Hematol Educ Program. 2017; 2017(1):338-45.

5. Tournilhac O, Garff-Tavernier ML, Tabrizi R, Nguyen-Quoc S, Legrand-Izadifar F, Combes $P$, et al. RIC allogeneic stem cell transplantation for high risk CLL followed by preemptive MRD-based immunointervention - final results from the phase II ICLL03 Ricac-Pmm trial (FILO - SFGM-TC French intergroup). Blood. 2017;130(Suppl 1):4599.

6. Gribben JG. How and when I do allogeneic transplant in CLL. Blood. 2018;132(1):31-9.

7. June $\mathrm{CH}$, O'Connor RS, Kawalekar OU, Ghassemi S, Milone MC. CAR T cell immunotherapy for human cancer. Science. 2018;359(6382):1361-5. 
8. Porter DL, Levine BL, Kalos M, Bagg A, June CH. Chimeric antigen receptormodified T cells in chronic lymphoid leukemia. N Engl J Med. 2011;365(8):725-33.

9. Brentjens RJ, Rivière I, Park JH, Davila ML, Wang X, Stefanski J, et al. Safety and persistence of adoptively transferred autologous CD19-targeted T cells in patients with relapsed or chemotherapy refractory B-cell leukemias. Blood. 2011;118(18):4817-28.

10. Kalos M, Levine BL, Porter DL, Katz S, Grupp SA, Bagg A, et al. T cells with chimeric antigen receptors have potent antitumor effects and can establish memory in patients with advanced leukemia. Sci Transl Med. 2011;3(95):95ra73.

11. Kochenderfer JN, Dudley ME, Feldman SA, Wilson WH, Spaner DE, Maric I, et al. B-cell depletion and remissions of malignancy along with cytokineassociated toxicity in a clinical trial of anti-CD19 chimeric-antigen-receptortransduced T cells. Blood. 2012;119(12):2709-20.

12. Cruz CRY, Micklethwaite KP, Savoldo B, Ramos CA, Lam S, Ku S, et al. Infusion of donor-derived CD19-redirected virus-specific T cells for B-cell malignancies relapsed after allogeneic stem cell transplant: a phase 1 study. Blood. 2013;122(17):2965-73.

13. Kochenderfer JN, Dudley ME, Kassim SH, Somerville RPT, Carpenter RO, Stetler-Stevenson M, et al. Chemotherapy-refractory diffuse large B-cell lymphoma and indolent B-cell malignancies can be effectively treated with autologous T cells expressing an anti-CD19 chimeric antigen receptor. J Clin Oncol Off J Am Soc Clin Oncol. 2015;33(6):540-9.

14. Porter DL, Hwang W-T, Frey NV, Lacey SF, Shaw PA, Loren AW, et al. Chimeric antigen receptor $T$ cells persist and induce sustained remissions in relapsed refractory chronic lymphocytic leukemia. Sci Transl Med. 2015; 7(303):303ra139.

15. Fraietta JA, Beckwith KA, Patel PR, Ruella M, Zheng Z, Barrett DM, et al. Ibrutinib enhances chimeric antigen receptor T-cell engraftment and efficacy in leukemia. Blood. 2016;127(9):1117-27.

16. Brudno JN, Somerville RPT, Shi V, Rose JJ, Halverson DC, Fowler DH, et al. Allogeneic T cells that express an anti-CD19 chimeric antigen receptor induce remissions of B-cell malignancies that progress after allogeneic hematopoietic stem-cell transplantation without causing graft-versus-host disease. J Clin Oncol Off J Am Soc Clin Oncol. 2016;34(10):1112-21.

17. Ramos CA, Savoldo B, Torrano V, Ballard B, Zhang H, Dakhova O, et al. Clinical responses with $T$ lymphocytes targeting malignancy-associated $\mathrm{K}$ light chains. J Clin Invest. 2016;126(7):2588-96.

18. Turtle CJ, Hay KA, Hanafi L-A, Li D, Cherian S, Chen X, et al. Durable molecular remissions in chronic lymphocytic leukemia treated with CD19specific chimeric antigen receptor-modified T cells after failure of ibrutinib. J Clin Oncol Off J Am Soc Clin Oncol. 2017;35(26):3010-20.

19. Geyer MB, Rivière I, Sénéchal $B$, Wang $X$, Wang $Y$, Purdon TJ, et al. Autologous CD19-targeted CAR T cells in patients with residual CLL following initial purine analog-based therapy. Mol Ther J Am Soc Gene Ther. 2018;26(8):1896-905.

20. Gauthier J, Hirayama AV, Hay KA, Li D, Lymp J, Sheih A, et al. Comparison of efficacy and toxicity of CD19-specific chimeric antigen receptor T-cells alone or in combination with ibrutinib for relapsed and/or refractory CLL. Blood. 2018;132(Suppl 1):299.

21. Gill SI, Vides V, Frey NV, Metzger S, O'Brien M, Hexner E, et al. Prospective clinical trial of anti-CD19 CAR T cells in combination with ibrutinib for the treatment of chronic lymphocytic leukemia shows a high response rate. Blood. 2018;132(Suppl 1):298.

22. Siddiqi T, Soumerai JD, Wierda WG, Dubovsky JA, Gillenwater HH, Gong L, et al. Rapid MRD-negative responses in patients with relapsed/refractory CLL treated with Liso-Cel, a CD19-directed CAR T-cell product: preliminary results from transcend CLL 004, a phase 1/2 study including patients with high-risk disease previously treated with ibrutinib. Blood. 2018;132(Suppl 1):300.

23. Fraietta JA, Lacey SF, Orlando EJ, Pruteanu-Malinici I, Gohil M, Lundh S, et al. Determinants of response and resistance to CD19 chimeric antigen receptor (CAR) T cell therapy of chronic lymphocytic leukemia. Nat Med. 2018;24(5):563-71.

24. Giordano Attianese GMP, Marin V, Hoyos V, Savoldo B, Pizzitola I, Tettamanti $S$, et al. In vitro and in vivo model of a novel immunotherapy approach for chronic lymphocytic leukemia by anti-CD23 chimeric antigen receptor. Blood. 2011;117(18):4736-45.

25. Faitschuk E, Hombach AA, Frenzel LP, Wendtner C-M, Abken H. Chimeric antigen receptor $T$ cells targeting $\mathrm{fc} \mu$ receptor selectively eliminate $C L L$ cells while sparing healthy B cells. Blood. 2016;128(13):1711-22.
26. Berger C, Sommermeyer D, Hudecek M, Berger M, Balakrishnan A, Paszkiewicz PJ, et al. Safety of targeting ROR1 in primates with chimeric antigen receptor-modified T cells. Cancer Immunol Res. 2015;3(2):206-16.

27. Zhao Z, Condomines M, van der Stegen SJC, Perna F, Kloss CC, Gunset G, et al. Structural design of engineered costimulation determines tumor rejection kinetics and persistence of CAR T cells. Cancer Cell. 2015;28(4):415-28.

28. Hoffmann J-M, Schubert M-L, Wang L, Hückelhoven A, Sellner L, Stock S, et al. Differences in expansion potential of naive chimeric antigen receptor $T$ cells from healthy donors and untreated chronic lymphocytic leukemia patients. Front Immunol. 2017;8:1956.

29. Mueller KT, Maude SL, Porter DL, Frey N, Wood P, Han X, et al. Cellular kinetics of CTL019 in relapsed/refractory B-cell acute lymphoblastic leukemia and chronic lymphocytic leukemia. Blood. 2017;130(21):2317-25.

30. Riches JC, Davies JK, McClanahan F, Fatah R, lqbal S, Agrawal S, et al. T cells from CLL patients exhibit features of T-cell exhaustion but retain capacity for cytokine production. Blood. 2013;121(9):1612-21.

31. Dubovsky JA, Beckwith KA, Natarajan G, Woyach JA, Jaglowski S, Zhong Y, et al. Ibrutinib is an irreversible molecular inhibitor of ITK driving a Th1selective pressure in T lymphocytes. Blood. 2013;122(15):2539-49.

32. Yin $Q$, Sivina M, Robins $H$, Yusko E, Vignali M, O'Brien S, et al. Ibrutinib therapy increases $T$ cell repertoire diversity in patients with chronic lymphocytic leukemia. J Immunol Baltim Md 1950. 2017;198(4):1740-7.

33. Long M, Beckwith K, Do P, Mundy BL, Gordon A, Lehman AM, et al. Ibrutinib treatment improves $T$ cell number and function in CLL patients. J Clin Invest. 2017;127(8):3052-64.

34. Neelapu SS, Locke FL, Bartlett NL, Lekakis L, Miklos DB, Jacobson CA, et al. Axicabtagene ciloleucel CAR T-cell therapy in refractory large B-cell lymphoma. N Engl J Med. 2017;377(26):2531-44.

35. Fraietta JA, Nobles CL, Sammons MA, Lundh S, Carty SA, Reich TJ, et al. Disruption of TET2 promotes the therapeutic efficacy of CD19-targeted T cells. Nature. 2018:558(7709):307-12.

\section{Publisher's Note}

Springer Nature remains neutral with regard to jurisdictional claims in published maps and institutional affiliations.

Ready to submit your research? Choose BMC and benefit from:

- fast, convenient online submission

- thorough peer review by experienced researchers in your field

- rapid publication on acceptance

- support for research data, including large and complex data types

- gold Open Access which fosters wider collaboration and increased citations

- maximum visibility for your research: over $100 \mathrm{M}$ website views per year

At BMC, research is always in progress.

Learn more biomedcentral.com/submissions 